\title{
Virtual Reality Hypnosis for Anxiety and Pain Management in Intensive Care Units. A Prospective Randomized Trial Among Cardiac Surgery Patients.
}

Floriane Marie Rousseaux ( $\nabla$ floriane.rousseaux@uliege.be )

Universite de Liege https://orcid.org/0000-0003-1998-5471

Nadia Dardenne

Universite de Liege

Paul B Massion

Centre hospitalier universitaire de Liege

Didier Ledoux

Centre hospitalier universitaire de Liege

Marie-Elisabeth Faymonville

Centre hospitalier universitaire de Liege

Anne-Sophie Nyssen

Universite de Liege

\section{Audrey Vanhaudenhuyse}

Centre hospitalier universitaire de Liege

\section{Research}

Keywords: cardiac surgery, intensive care units, hypnosis, non-pharmacological approaches, preoperative anxiety, postoperative pain, virtual reality, virtual reality hypnosis

Posted Date: August 20th, 2020

DOI: https://doi.org/10.21203/rs.3.rs-60523/v1

License: (c) (1) This work is licensed under a Creative Commons Attribution 4.0 International License. Read Full License

Version of Record: A version of this preprint was published at European Journal of Anaesthesiology on November 15th, 2021. See the published version at https://doi.org/10.1097/EJA.0000000000001633. 


\section{Abstract}

Background: Although non-pharmacological tools are nowadays commonly used in medical settings, virtual reality and hypnosis are little studied in complex contexts such as intensive care, where patients need significant physical and psychological assistance. The aim of the project is to evaluate the benefits of hypnosis, virtual reality (VR) and the combination of hypnosis and virtual reality (VRH) on anxiety and pain on patients before and after a cardiac surgery.

Methods: This prospective randomized and controlled clinical trial was conducted in the University Hospital of Liege (Belgium). Participants are adults undergoing cardiac surgery, French speaking. Exclusion criteria are patients with psychiatric diseases, claustrophobia, acrophobia, heavy hearing impairment, visual impairment, extreme fatigue, verbal incoherence, surgery cancelled or postponed. The day before the surgery, patients were randomly assigned to four arms (control, hypnosis, VR and VRH) and had 20 minutes of one of the technique. They received the same intervention one day after surgery, in intensive care units. Anxiety, pain, fatigue, relaxation and physiological parameters were evaluated before and after each session.

Results: 100 patients ( $66.38 \pm 11.48$ years; 76 men, 24 women) were included. Results showed that anxiety decreased from baseline to postoperative day in all groups. Relaxation increased in all groups in preoperative $(p=.000)$ and postoperative period $(p=0.03)$. There were no significant results for pain and fatigue $(p>0.05)$. There was no significant difference between control group and hypnosis, VR or VRH.

Conclusion: Anxiety decreased and relaxation increased in all groups, including control group. We cannot affirm that one technique is better than another is. Nevertheless, this study helps to expand the knowledge regarding application of virtual reality, hypnosis and virtual reality hypnosis in the specific contexts of cardiac surgery and intensive care units. Additional studies are required to compare and evaluate the costs-effectiveness of these techniques for critical care patients and caregivers (see Figure 1).

Trial registration: ClinicalTrials.gov: NCT03820700. https://clinicaltrials.gov/ct2/show/NCT03820700. Registered on January 29 2019. Retrospectively registered.

\section{Key Messages}

- Virtual reality is increasingly used in medical practice for painful procedures. Virtual reality is presented as the new tool to be used in medicine, nevertheless, guidelines about his utilization are not clear. Besides, it is little studied in complex contexts such as intensive care, where the patient needs significant physical and psychological assistance.

- Hypnosis has demonstrated for many years its effectiveness in reducing pain and emotional distress in patients. However, the field of use of hypnosis in intensive care has not yet been widely explored. Moreover, the combination of the two techniques together is the subject of many questions both in terms of effectiveness and in terms of the fundamental mechanisms underlying these techniques. 
- This study is the first to combine and compare hypnosis and virtual reality together and investigate the perceived usefulness to the critical care patient in a randomized clinical trial.

- Our study suggests that these complementary techniques can be easily used in complex medical care such as intensive care units (before and after a cardiac surgery), nevertheless, their effectiveness for the management of anxiety and pain is being questioned by our results who did not demonstrate any additional effects from virtual reality hypnosis than single hypnosis; standard virtual reality or control group, which is in contrast with the literature/ previous studies and general expectancies about these complementary approaches.

\section{Introduction}

Patients who are undergoing a cardiac surgery are exposed to psychological and physiological distress (1). Anxiety and catastrophizing before surgery can be associated with impaired recovery after surgery such as persistent pain and more risks for complicated wake-up after surgery (2-4). Moreover, the stay in intensive care units could be source of additional stress, confusional state, cognitive dysfunction and depression (5).

Today non-pharmacological techniques (e.g. music, relaxation, hypnosis) are used together with pharmacological treatment and have been shown to decrease perioperative anxiety, pain, medication requirement, and nausea/vomiting (1, 6-9). Hypnosis and virtual reality (VR) have been investigated in numerous studies in the medical field (e.g. algology, oncology, anesthesia) to reduce pain and anxiety and increase patients' comfort (10-13). Hypnosis is defined as a "state of modified consciousness involving focused attention and reduced peripheral awareness characterized by an enhanced capacity for response to suggestions" (14). The hypnotic state involves the capacities of absorption (tendency to be fully involved in a mental experience), dissociation (a mental separation from the environment) and suggestibility (the responsiveness and ability to follow hypnotic suggestions) (15). Hypnosis can be used during surgery in combination with local anesthesia and conscious sedation. This technique is called "hypnosedation" and is significantly effective in decreasing anxiety and pain, analgesic drugs and increase comfort, optimal surgical conditions and faster recovery (16). A meta-analysis of 26 randomized clinical trials showed a significantly large positive effect size in favor of hypnosis for the reduction of emotional distress among patients undergoing medical procedures (e.g. CABG, abdominal surgery, plastic surgery) (17-20). Despite the reduction in postoperative behavioral disorders and no adverse effects risks (16), hypnosis can be difficult to organize on a routine because it is often time-consuming and requires qualified and available therapists (2). Virtual reality (VR) is a technique involving the "use of computer technology to create the effect of an interactive three-dimensional world in which the objects have a spatial presence" (21). VR allows to reduce preoperative stress with no side effects and with no need of additional medical staff (22). In a prospective study conducted with 20 patients in maxillofacial surgery, five minutes of a VR movie reduced significantly the stress level of patients, and reduced the salivary cortisol which is a physiological indicator of stress (2). As both VR and hypnosis are effective in the reduction of anxiety and pain, a few studies compared and combined these tools together. This tool is 
today known as virtual reality hypnosis $(\mathrm{VRH})(23)$. Although VRH showed is effectiveness in the management of anxiety and pain in different medical contexts such as physical trauma, chronic pain management or intensive care units $(12,24-26)$, to our knowledge, VRH has not yet been used during pre and postoperative cardiac surgery.

Nowadays, randomized studies are needed to investigate and compare the effectiveness of these techniques in pre-surgery and intensive care units (ICU). Our hypothesis is that VRH could be an added value in the reduction of pain and anxiety before and after cardiac surgery, as previously mentioned by authors studying the effect of VRH on experimental pain $(27,28)$. We here compare the effects of standardized audio hypnosis, VR, and VRH on patients' anxiety, pain and physiological variables in the pre-operative period as well as during the post-operative recovery of patients in ICU.

\section{Methods}

\section{Objectives}

The aim is to identify the evolution of self-assessed anxiety, pain, fatigue, and relaxation states of cardiac surgery patients before and after using hypnosis, virtual reality and virtual reality hypnosis as compared with a control group.

\section{Registration}

This trial was registered on clinicaltrials.gov with the trial identification number NCT03820700 (https://clinicaltrials.gov/ct2/show/NCT03820700). Registered on 29 January 2019. Retrospectively registered. The recruitment started in October 2018 and closed in January 2020. Registration was prospective before enrolling the first patient. The complete protocol of the study has previously been published and displayed detailed information about the study design, the recruitment procedures, and the assessment and intervention components (29). Therefore, we will only summarize these aspects in this section.

\section{Recruitment and patient involvement}

Patients and public were involved at several stages of the trial, including the choice of the questionnaires and the evaluation of the virtual reality setting. The final study protocol was designed beforehand thanks to pilot participants. There is no plan to individually identify and notify patients about the results of this study.

Randomization was done with blocks of 5 before initial contact with patients. Initial contact between the investigator and the patient took place one day before cardiac surgery, at the hospital. Patients included were adults undergoing cardiac surgery (coronary artery bypass graft (CAB); mitral valve replacement (MVR); aortic valve replacement (AVR); others) who have given consent for their participation. All the study and surgeries were conducted in the University Hospital of Liege (Belgium). Inclusion criteria were the following: adults (>18 years), French speaking, undergoing cardiac surgery, Glasgow Coma Scale 
score $>14,(30)$ Richmond Agitation-Sedation Scale score comprised of -1 and +1 (31). Exclusion criteria were the following: psychiatric diseases, claustrophobia, acrophobia, heavy hearing or visual impairment, extreme fatigue, verbal incoherence, surgery cancelled or postponed. After explanations about the tools used, patients included were asked to participate to the study and fill in the consent form. They answered to the investigator's questions and had a session of one technique in their hospital room and another after the surgery.

\section{Intervention components}

This study is a prospective randomized study, single-center trial with four arms, including three experimental groups and one control group. Participants were randomly included in the following conditions:

(1) Control group: daily standard care.

(2) Hypnosis: daily standard care combined with 20-minutes hypnosis session. Hypnosis exercise was created and recorded by M-E Faymonville and A-S. Nyssen, both experts in clinical and experimental hypnosis. The recording, named "Soothing white clouds", included suggestions about relaxation, positive body sensations, invitation to observe a sunrise and a beautiful landscape meanwhile relaxing in a white cloud chair.

(3) Virtual reality (VR): daily standard care combined with VR session. Investigator used a head-mounted 3D graphical display with goggles, created by Oncomfort $\odot$. With this tool, participants watched a 3D immersive landscape for 20 minutes consisting of a shed near a lake at sunrise followed by a relaxing moment in the clouds. The session ends on the lake's edge (Fig. 1).

(4) Virtual reality hypnosis combination (VRH): daily standard care combined with VRH session. Soothing white clouds hypnosis session was combined to 3D visual movie (immersive landscape and relaxing moment in the clouds by Oncomfort ( )), with a duration of 20 minutes.

\section{Assessment}

Demographic data were recorded (age, gender, type of surgery, alcohol and tobacco use) as well as psychological measures (anxiety, pain, fatigue, relaxation) and physiological data (heart rate, arterial pressure, respiratory rate, oxygen saturation, pupil size). The primary outcome, anxiety, was assessed with the Visual Analogic Scale (VAS) before and after the 20 minutes' sessions of the intervention. Secondary outcomes measured with VAS are pain, relaxation and fatigue. The VAS score helps to determine the intensity of these variables, as subjectively assessed by the patient, on a scale ranging from 0 to 10. Physiological parameters such as heart rate, arterial pressure, respiratory rate, oxygen saturation, pupil size were recorded directly on the patient's bed monitor. Demographic factors have been also recorded and included in analysis: age and gender, surgery time, cardiac surgery type (aortic valve replacement, mitral valve replacement, coronary artery bypass surgery, other), alcohol consumption, use of tobacco, medication. Daily dissociative profile of participants have been assessed with the 
Dissociative Experience Scale (DES) 28-items (32). Hypnosis, VR, VRH or nothing (control group) were applied for 20 minutes' sessions: the day before surgery (Day- 1 at 5 pm) and the day after (Day +1 at least $24 \mathrm{~h}$ after surgery). Before and after the session, physiological and psychological parameters were recorded (See Fig. 2).

\section{Statistical analyses}

The sample size calculation was based on repeated measures ANOVA test. Alpha was set at 0.05, power at $95 \%$ and the standardized effect size at 0.5 . Studies which aim to assess the effect of hypnosis on the patients' pre-surgery anxiety considered that an effect size of 0.2 was considered small, 0.5 moderate and 0.8 large (1). According to this analysis, 12 patients are required in each group for a total of 48 patients. We decided to enroll one hundred patients (25 per group) to compensate possible dropouts on the postoperative day. Normality was investigated graphically with histogram and quantile-quantile plot and was tested by using the Shapiro-Wilk test. Continuous variables were reported as means ( \pm standard deviation) or medians (interquartile range) for skewed distributions, while the number and percentages were given for qualitative variables. Homogeneity of the four groups were assessed with Chi-squared Test for qualitative and dichotomous variables and with a one-way analysis of variance (ANOVA-1) or the nonparametric Kruskal-Wallis test for the quantitative variables. A repeated measures ANOVA test was used to compare the evolution of the parameters between Day - 1 and Day +1 morning and afternoon according to the groups. This analysis was adjusted by the potential confounding factors. Calculations were always carried out on the maximum number of data available. Results were considered as statistically significant at the $5 \%$ critical level $(p<0.05)$. Analyses were performed using R 3.5.3 (R Core Team) and the package Rcommander (Rcmdr) and using SAS 9.4 (C SAS Institute Inc., Cary, NC, USA).

\section{Results}

\section{Study population}

Between October 2018 and November 2019, a total of 100 patients were randomized in four arms (Figure 3). Of 100 patients enrolled for the session of pre-operative day, 30 (30\%) of patients dropped out on post-surgery day (T3) due to fatigue, sedation or confusion, patients who were intubated and sedated or in the recovery room, patients who did not like hypnosis, VR or $\mathrm{VRH}$, or if caregivers were giving heavy care to the patient. Analysis were conducted on 100 patients in the preoperative day (T0-T1) and 70 patients in post-surgery day (T2-T3) in the mixed model. The study sample at baseline consisted of 76 of males and 24 of females. The general mean patients age was $66 \pm 11$ years. Fifty-seven (57\%) of patients undergone a coronary artery bypass graft surgery (CABG), 26 (26\%) a mitral valve replacement (MVR), 9 (9\%) aortic valve replacement (AVR) or others 8 (8\%). Participants were $40(40 \%)$ to consume more than 3 glasses of alcohol by week and 33 (33\%) of participants smoked. Patients characteristics (age, gender, alcohol and tobacco consumption were well balanced between the four arms, except for the type of surgery $(p=.002)$. This was corrected in the analysis (Table 1). 
Table 1

Patients characteristics by groups at baseline (TO)

\begin{tabular}{|c|c|c|c|c|c|c|}
\hline & $\begin{array}{l}\text { Control } \\
(n=25)\end{array}$ & $\begin{array}{l}\text { Hypnosis } \\
(n=25)\end{array}$ & $\begin{array}{l}\text { Virtual } \\
\text { Reality } \\
(n=25)\end{array}$ & $\begin{array}{l}\text { Virtual reality/ } \\
\text { Hypnosis } \\
(n=25)\end{array}$ & $\begin{array}{l}\text { TOTAL } \\
(n=100)\end{array}$ & $\begin{array}{l}P \\
\text { value }\end{array}$ \\
\hline $\begin{array}{l}\text { Age } \\
\text { (mean } \pm \text { standard } \\
\text { deviation) }\end{array}$ & $\begin{array}{l}63.36( \\
\pm 11.49)\end{array}$ & $\begin{array}{l}67.56( \\
\pm 12.45)\end{array}$ & $\begin{array}{l}64.72( \\
\pm 13.44)\end{array}$ & $\begin{array}{l}68.04 \\
\pm 7.78)\end{array}$ & $\begin{array}{l}66.18 \\
( \\
\pm 11,48)\end{array}$ & \\
\hline Gender & & & & & & .72 \\
\hline Male & 18 & 18 & 19 & 21 & 76 & \\
\hline Female & 7 & 7 & 6 & 4 & 24 & \\
\hline Alcohol consumers & 10 & 11 & 7 & 11 & 40 & .61 \\
\hline Tobacco consumers & 4 & 5 & 8 & 4 & 33 & .45 \\
\hline Surgery type & & & & & & $.002 *$ \\
\hline $\begin{array}{l}\text { Coronary artery bypass } \\
\text { graft surgery }\end{array}$ & 10 & 15 & 17 & 15 & 57 & \\
\hline $\begin{array}{l}\text { Mitral valve } \\
\text { replacement }\end{array}$ & 3 & 9 & 6 & 8 & 26 & \\
\hline $\begin{array}{l}\text { Mitral valve } \\
\text { replacement }\end{array}$ & 6 & 1 & 0 & 2 & 9 & \\
\hline Multiple interventions & 4 & 0 & 0 & 0 & 4 & \\
\hline Others & 2 & 0 & 2 & 0 & 4 & \\
\hline
\end{tabular}

\section{Primary endpoint: anxiety}

The mean (SD) anxiety score assessed at baseline was $5.38( \pm 2.89)$ in the control group, $5.53 \pm 3.16)$ in the hypnosis group, $4.48 \pm 3.02$ ) in the VR group and $3.72 \pm 3.07$ ) in the VRH group. Of the 100 patients, 23 $(23 \%)$ patients reported high levels anxiety (score $>7$ ) at baseline. Anxiety is higher at baseline (T0) than at T1 $(p<0.000)$, T2 $(p<0.000)$ and T3 $(p<0.000)$ in all groups. There was a different evolution of anxiety over time according group ( $\mathrm{p}=0.023)$ : patients in hypnosis group reported significantly more anxiety than those in VRH group at all times $(p=0.007)$. There were no other differences between groups. Anxiety was significantly associated with age $(p=0.017)$ : older subjects are more anxious at baseline. No others demographic characteristics are correlated with anxiety. Detailed score can be read in the supplementary files and figure 4 . 


\section{Secondary endpoints: pain, fatigue, relaxation}

Pain is correlated with time $(\mathrm{p}<0.000)$ and was lower at baseline $(\mathrm{T} 0)$ and at T1 as compared with T2 and T3 in all groups $(p<0.000)$. No demographic factors are correlated with pain. No difference in the pain scores was observed between the four groups, all groups progressed in the same way (see figure 5).

As pain, fatigue is correlated with time $(\mathrm{p}<0.000)$, levels of fatigue were lower at T0 and T1 than at T2 and T3 in all groups $(p<0.000)$. There is no difference between T0 and T1. Levels of fatigue before and after surgery were similar in the four groups. Gender is associated with fatigue, women felt more fatigue than men independently of the moment and group $(p=0.009)$.

There were differences between times for relaxation $(p=0.013)$ : patients at T0 felt less relax than at T1 $(p=0.008)$ and T3 $(p=0.008)$ in all groups. After the surgery, patients felt more relax at T3 than at T2 in all groups $(p=0.039)$.

\section{Physiological assessments}

Arterial pressure depended on the time assessment. Levels of arterial pressure were more elevated at T0 than at T1 $(p=0.030), T 2(p<0.000)$ and T3 $(p<0.000)$ in all groups. At the opposite, heart rate was lower at baseline (T0) and at T1 before the surgery than at T2 and T3 after the surgery $(p<0.000)$. There was no difference between groups at any moments. Tobacco consumption influenced the pupil size which was smaller for non-smoking patients $(p=0.036)$. Interventions did not affect oxygen saturation or respiratory frequency at any moment.

\section{Discussion}

In this study, we evaluated the influence of recorded hypnosis, VR and VRH on anxiety, pain, fatigue and relaxation by using VAS and physiological parameters in pre and post cardiac surgery, before and after each session of VR, VRH or hypnosis. Patients received one session (20 minutes) before the surgery and one session 24 hours after surgery when they are in ICU. No differences between the four groups (control; hypnosis; VR; VRH) were found at any time for any variable, diminution of physiological parameters are not clinically relevant. We showed that patients in hypnosis group were more anxious at baseline and that this difference pursued at all times (regardless of the group). Thus we cannot conclude that one of the technique was more efficient to reduce anxiety, pain or any other variable assessed comparing to control group.

Our results are in contrast to some studies evaluating the effects of hypnosis to reduce anxiety in surgery and in ICU (for a review see (33)). Montgomery et al. (2007) showed that a brief hypnosis session (15 minutes) performed within 1 hour before breast surgery reduced pain, nausea, emotional upset and their comfort was improved (34). In a randomized trial on 50 patients, hypnosis was administrated before and after the CABG surgery. Authors found a significant difference between hypnosis group and control group 
in terms of using coping strategies for emotional distress, anxiety and depression decrease (18). A prospective randomized controlled trial investigated the benefits of psychological therapy with positive hypnotic suggestions on 60 patients in ICU and showed a significant diminution of the ventilation period and the length of stay in ICU in the hypnosis group (compared to the control group) (35). VR was also documented as a beneficial tool to reduce anxiety before surgery. Mosso-Vasquez et al. (2014) gave to 67 patients 30 minutes of VR $24 \mathrm{~h}$ before cardiac surgery. According to the authors, $88 \%$ of patients reported a decreased level of pain experienced post-therapy; $37 \%$ experienced reduced heart rate; $52 \%$ experienced reduced mean arterial pressure. However, these results are limited by the non-controlled design of the study (36). Although hypnosis and VR are well documented in the literature, a few studies used the combination of both (VRH) or compare them in their protocol. We recently identified 8 studies about VRH and pain that showed VRH as useful for pain and anxiety reduction in different clinical settings such as chronic pain, burn pain and physical trauma (26). However, most of the investigations are case studies and results about VRH and pain did not show consistent efficacy for all patients all the days (22-24). A non-randomized trial of $59 \mathrm{ICU}$ patients showed significant reduction of anxiety and depression with VR combined with guided meditation every day in a week (no effects were found for pain, sleep and physiological parameters) (25).

In our study, because of the lack of differences between groups, results did not tell us about the value of adding VR to hypnosis in terms of clinical efficacy. This question remains unsolved in the literature. Only two previous studies compared hypnosis, VR and VRH but in healthy subjects. According to Enea et al (2014), highly hypnotizable subjects reported less pain when using hypnotic tools (hypnosis and VRH), while low hypnotizable subjects reported less pain when using VR and VRH than hypnosis alone or no treatment (27). In addition, it seems that post-hypnotic analgesia is dependent of the hypnotizability level to reduce pain intensity, whereas VR is not (28). Regarding these results, we could argue that VR and hypnosis involve different mechanisms for pain reduction. These two randomized trials hypothesized that the cognitive processes involved in distraction during VR differ from those involved in hypnosis (27, 28). The authors suggested that hypnosis and VR differ in the mechanism of how they reduce pain (27, 28). This hypothesis should be investigated in large samples with validated scales. More randomized controlled trials are needed to investigate the effects of VRH on anxiety and pain in comparison to others techniques in patients as well as healthy subjects. More studies are required to improve the comparison of the techniques in terms of efficacy and cognitive functions.

\section{Strengths and limits}

One limitation of our study is the patients' dropout due to the inability to participate the day after the surgery. Some of the patients expressed the fact that extreme fatigue as well as deep sedation due to surgery are a barrier to follow hypnotic suggestions and VR movie properly. The second limitation is that given the nature of our intervention, neither patients nor the investigators were blinded to the treatment assignment. Third, the standardization of the tools: this methodological strength can be considered as a clinical limit in that these techniques cannot be adapted to the patient situation. Hypnosis is a strong technique to reduce anxiety and pain and the quality of therapist-patient relationship is essential for the 
therapist adaptability, which a recording does not allow. More trials are required to study the best way to use hypnosis/ virtual reality in intensive care units.

The randomized controlled design is a strength of our study for the comparison of non-pharmacological techniques. To our knowledge, two studies compared hypnosis, VR and VR/hypnosis $(27,28)$.

Nevertheless, these studies assessed experimental pain in healthy subjects. Our study is the first to investigate the clinical efficacy of these techniques among patients in cardiac surgery in ICU and the results challenge the current frenzy around virtual reality in the medical field, the high expectations that stem from it and the willingness to use it in any situation. This study reveals the necessity of applying non-pharmacological tools at different times and in different medical contexts to judge about their appropriateness for the patients' needs. Clinicians have to take into account pain and distress following cardiac surgery and determine what could be an appropriate therapy for each patient in addition to inform them about self-management strategies (such as hypnosis). A recent meta-analysis showed that active perioperative psychological intervention (education, relaxation, guided imagery, physical or cognitive behavioral therapies) moderately reduced persistent postsurgical pain and physical impairment (37). They concluded that researchers and clinicians have to reduce non-dispensable treatments by identifying high-risk patients that are more likely to benefit from psychotherapies and nonpharmacological techniques, in other terms, to adapt the therapy to the patient (37).

\section{Conclusion}

This randomized trial is the first to compare hypnosis, VR and VRH during pre and post-surgery in ICU by studying the specific population of cardiac surgery patients. Our results showed that neither VR, $\mathrm{H}$ nor VRH seemed effective to reduce anxiety and pain when it was assessed before and after the surgery. With this study, we cannot confirm that there is a difference between the techniques in term of effectiveness. At a fundamental level, future randomized controlled trials could tell us what are the phenomenological differences between hypnosis, VR and VRH. Regarding of clinical practice, further studies will then be developed to extend and adapt this protocol to others non-pharmacological techniques and to other population of patients in ICU.

\section{Abbreviations}

AVR: Aortic Valve Replacement

C: Control group

CAB: Coronary Artery Bypass Graft

$\mathrm{H}$ : Hypnosis group

ICU: Intensive Care Units 
MVR: Mitral Heart Valve Replacement

VAS: Visual Analogical Scale

VR: Virtual Reality

VRH: Virtual Reality Hypnosis

\section{Declarations}

\section{Ethical approval and consent to participate}

This study has been approved by the Ethics Committee of the Faculty of Medicine and the Ethics Committee of the Faculty of Psychology, Speech Therapy and Educational Sciences of the University of Liege. Written informed consents were obtained from all patients before inclusion. There is no plan to individually notify participants regarding the results of this study. All patients have provided their signed consent to publication and submitted as a supplemental file.

\section{Consent for publication}

Not applicable.

\section{Availability of data and materials}

The datasets supporting the conclusions of this article are included within the article (and its additional file(s)). Others requests for access to data and statistical code should be addressed to FR or AV.

FR and AV guaranty that the manuscript is an honest, accurate, and transparent account of the study being reported; that no important aspects of the study have been omitted; and that any discrepancies from the study as planned (and, if relevant, registered) have been explained.

\section{Competing interest}

Marie-Elisabeth Faymonville is part of a scientific board of Oncomfort society (www.oncomfort.com). The University of Liege and Hospital University of Liege undertake to mention in the relevant publications the use of a modified product compared to Oncomfort's commercial product. Other authors report no conflicts of interest in this work. All others authors have completed the ICMJE uniform disclosure form at www.icmje.org/coi_disclosure.pdf and declare: all authors had financial support from University of Liege for the submitted work; no financial relationships with any organizations that might have an interest in the submitted work in the previous three years; no other relationships or activities that could appear to have influenced the submitted work. 


\section{Funding}

Funding cover fees of PhD student (FR), post-doc researcher (AV) and material. This work was supported by the University and University Hospital of Liege, the Benoit Foundation (Bruxelles, Belgium), the NonFria Grant (University of Liege, Belgium) and the Credits Sectoriels de la Recherche (University of Liege, Belgium). Researchers are independents from funders.

\section{Author's contribution}

FR is guarantor. Design and conception of the study: all authors. Project supervisors: AV, ASN. Acquisition of data: FR. Material conception and hypnosis voice recording: MEF, ASN. Statistical analysis: FR and ND. Interpretation of data: all authors. Writing up of the first draft: FR. Revision of the draft: all authors. Revision of the final draft: FR and AV. Read and approved the final manuscript: all authors.

\section{Acknowledgements}

The authors would like to thanks the University and University Hospital of Liege, the Benoit Fundation (Bruxelles, Belgium) and the Non-Fria Grant (Liege, Belgium) for their financial contribution. Thanks to all departments of the University Hospital of Liege involved in the project: Cardiac Surgery Department, Algology Department, Department of Intensive Care Units. Thanks to Oncomfort Society (www.oncomfort.com) (Wavre) and Musicotherapy and Counselling (www.musicotherapeute.be) (Liege) for providing the material.

\section{References}

1. Akgul A, Guner B, Çırak M, Çelik D, Hergünsel O, Bedirhan S. The beneficial effect of hypnosis in elective cardiac surgery: A preliminary study. Thorac Cardiovasc Surg 4 avr. 2016;64(07):581-8.

2. Ganry L, Hersant B, Sidahmed-Mezi M, Dhonneur G, Meningaud JP. Using virtual reality to control preoperative anxiety in ambulatory surgery patients: A pilot study in maxillofacial and plastic surgery. J Stomatol Oral Maxillofac Surg sept. 2018;119(4):257-61.

3. Johansen A, Romundstad L, Nielsen C, Schirmer H, Stubhaug A. Persistent postsurgical pain in a general population: Prevalence and predictors in the Tromso study. Pain juill. 2012;153(7):1390-6.

4. Mavros MN, Athanasiou S, Gkegkes ID, Polyzos KA, Peppas G, Falagas ME. Do psychological variables affect early surgical recovery? PLoS ONE [Internet]. 25 mai 2011 [cité 6 août 2020];6(5). Disponible sur: https://www.ncbi.nlm.nih.gov/pmc/articles/PMC3102096/.

5. Rovai D, Giannessi D, Andreassi M, Gentili C, Pingitore A, Glauber M, et al. Mind injuries after cardiac surgery. J Cardiovasc Med déc. 2015;16(12):844-51.

6. Ames N, Shuford R, Yang L, Moriyama B, Frey M, Wilson F, et al. Music listening among postoperative patients in the intensive care unit: A randomized controlled trial with mixed-methods analysis. Integr 
Med Insights. 2017;12:117863371771645.

7. Lang EV, Benotsch EG, Fick LJ, Lutgendorf S, Berbaum ML, Berbaum KS, et al. Adjunctive nonpharmacological analgesia for invasive medical procedures: A randomised trial. The Lancet 29 avr. 2000;355(9214):1486-90.

8. Meurisse M, Hamoir E, Defechereux T, Gollogly L, Derry O, Postal A, et al. Bilateral neck exploration under hypnosedation: A new standard of care in primary hyperparathyroidism? Ann Surg mars. 1999;229(3):401-8.

9. Faymonville ME, Fissette J, Mambourg PH, Roediger L, Joris J, Lamy M. Hypnosis as adjunct therapy in conscious sedation for plastic surgery. Reg Anesth avr. 1995;20(2):145-51.

10. Grégoire C, Nicolas H, Bragard I, Delevallez F, Merckaert I, Razavi D, et al. Efficacy of a hypnosisbased intervention to improve well-being during cancer: A comparison between prostate and breast cancer patients. BMC Cancer. 22 juin 2018;18(1):677.

11. Indovina P, Barone D, Gallo L, Chirico A, De Pietro G, Giordano A. Virtual reality as a distraction intervention to relieve pain and distress during medical procedures: A comprehensive literature review. Clin J Pain. 2018;34(9):858-77.

12. Patterson DR, Jensen MP, Wiechman SA, Sharar SR. Virtual reality hypnosis for pain associated with recovery from physical trauma. Int J Clin Exp Hypn juill. 2010;58(3):288-300.

13. Vanhaudenhuyse A, Gillet A, Malaise N, Salamun I, Grosdent S, Maquet D, et al. Psychological interventions influence patients' attitudes and beliefs about their chronic pain. J Tradit Complement Med avr. 2018;8(2):296-302.

14. Elkins GR, Barabasz AF, Council JR, Spiegel D. Advancing research and practice: The revised APA Division 30 definition of hypnosis. Int J Clin Exp Hypn. 2015;63(1):1-9.

15. Spiegel D. Neurophysiological correlates of hypnosis and dissociation. J Neuropsychiatry Clin Neurosci. 1991;3(4):440-5.

16. Faymonville ME, Meurisse M, Fissette J. Hypnosedation. A valuable alternative to traditional anaesthetic techniques. Acta Chir Belg août. 1999;99(4):141-6.

17. Ashton RC, Whitworth GC, Seldomridge JA, Shapiro PA, Michler RE, Smith CR, et al. The effects of self-hypnosis on quality of life following coronary artery bypass surgery: Preliminary results of a prospective, randomized trial. J Altern Complement Med. 1 juin 1995;1(3):285-90.

18. de Klerk JE, du Plessis WF, Steyn HS, Botha M. Hypnotherapeutic ego strengthening with male South African coronary artery bypass patients. Am J Clin Hypn oct. 2004;47(2):79-92.

19. Faymonville EM, Mambourg HP, Joris J, Vrijens B, Fissette J, Albert A, et al. Psychological approaches during conscious sedation. Hypnosis versus stress reducing strategies: A prospective randomized study. Pain déc. 1997;73(3):361-7.

20. Schnur JB, Kafer I, Marcus C, Montgomery GH. Hypnosis to manage distress related to medical procedures: A meta-analysis. Contemp Hypn sept. 2008;25(3-4):114-28. 
21. Bryson S. Virtual Reality. A Definition History - A Personal Essay. ArXiv13124322 Cs [Internet]. 16 déc 2013 [cité 13 mai 2020]; Disponible sur: http://arxiv.org/abs/1312.4322.

22. Patterson DR, Wiechman SA, Jensen M, Sharar SR. Hypnosis delivered through immersive virtual reality for burn pain: A clinical case series. Int J Clin Exp Hypn juill. 2006;54(2):130-42.

23. Patterson DR, Tininenko JR, Schmidt AE, Sharar SR. Virtual reality hypnosis: a case report. Int J Clin Exp Hypn 1 janv. 2004;52(1):27-38.

24. Oneal BJ, Patterson DR, Soltani M, Teeley A, Jensen MP. Virtual reality hypnosis in the treatment of chronic neuropathic pain: A case report. Int J Clin Exp Hypn 2 sept. 2008;56(4):451-62.

25. Ong TL, Ruppert MM, Akbar M, Rashidi P, Ozrazgat-Baslanti T, Bihorac A, et al. Improving the intensive care patient experience with virtual reality-A feasibility study. Crit Care Explor juin. 2020;2(6):e0122.

26. Rousseaux F, Bicego A, Ledoux D, Massion P, Nyssen A-S, Faymonville M-E, et al. Hypnosis associated with $3 \mathrm{D}$ immersive virtual reality technology in the management of pain: A review of the literature. J Pain Res. 2020;13:1129-38.

27. Enea V, Dafinoiu I, Opriş D, David D. Effects of hypnotic analgesia and virtual reality on the reduction of experimental pain among high and low hypnotizables. Int J Clin Exp Hypn 3 juill. 2014;62(3):36077.

28. Patterson DR, Hoffman HG, Palacios AG, Jensen MJ. Analgesic effects of posthypnotic suggestions and virtual reality distraction on thermal pain. J Abnorm Psychol. 2006;115(4):834-41.

29. Rousseaux F, Faymonville M-E, Nyssen A-S, Dardenne N, Ledoux D, Massion PB, et al. Can hypnosis and virtual reality reduce anxiety, pain and fatigue among patients who undergo cardiac surgery: $A$ randomised controlled trial. Trials 15 avr. 2020;21(1):330.

30. Teasdale G, Jennett B. Assessment of coma and impaired consciousness: A practical scale. The Lancet 13 juill. 1974;304(7872):81-4.

31. Sessler CN, Gosnell MS, Grap MJ, Brophy GM, O'Neal PV, Keane KA, et al. The Richmond AgitationSedation Scale. Am J Respir Crit Care Med. nov 2002;15(10):1338-44. 166(.

32. Bernstein EM, Putnam FW. Development, reliability, and validity of a dissociation scale. J Nerv Ment Dis déc. 1986;174(12):727-35.

33. Can hypnosis be used in Intensive Care Units? Médecine Intensive Réanimation [Internet]. 6 août 2020 [cité 6

Rousseaux F, Bicego A, Malengreaux C, Faymonville M-E, Ledoux D, Massion PB, et al. Can hypnosis be used in Intensive Care Units? Médecine Intensive Réanimation [Internet]. 6 août 2020 [cité 6 août 2020]; Disponible sur: https://revue-mir.srlf.org/index.php/mir/article/view/87.

34. Montgomery GH, Bovbjerg DH, Schnur JB, David D, Goldfarb A, Weltz CR, et al. A randomized clinical trial of a brief hypnosis intervention to control side effects in breast surgery patients. J Natl Cancer Inst 5 sept. 2007;99(17):1304-12.

35. Szilágyi K, Diószeghy A, Benczúr C, Varga L. K. Effectiveness of psychological support based on positive suggestion with the ventilated patient. Eur J Ment Health 1 déc. 2007;2(2):149-70. 
36. Mosso-Vázquez JL, Gao K, Wiederhold BK, Wiederhold MD. Virtual reality for pain management in cardiac surgery. Cyberpsychology Behav Soc Netw juin. 2014;17(6):371-8.

37. Wang L, Chang Y, Kennedy SA, Hong PJ, Chow N, Couban RJ, et al. Perioperative psychotherapy for persistent post-surgical pain and physical impairment: A meta-analysis of randomised trials. $\mathrm{Br} \mathrm{J}$ Anaesth 1 juin. 2018;120(6):1304-14.

\section{Figures}

\section{Introduction}

The aim of the project is to evaluate the benefits of hypnosis, virtual reality (VR) and the combination of hypnosis and virtual reality (VRH) on anxiety and pain on patients before and after a cardiac surgery.

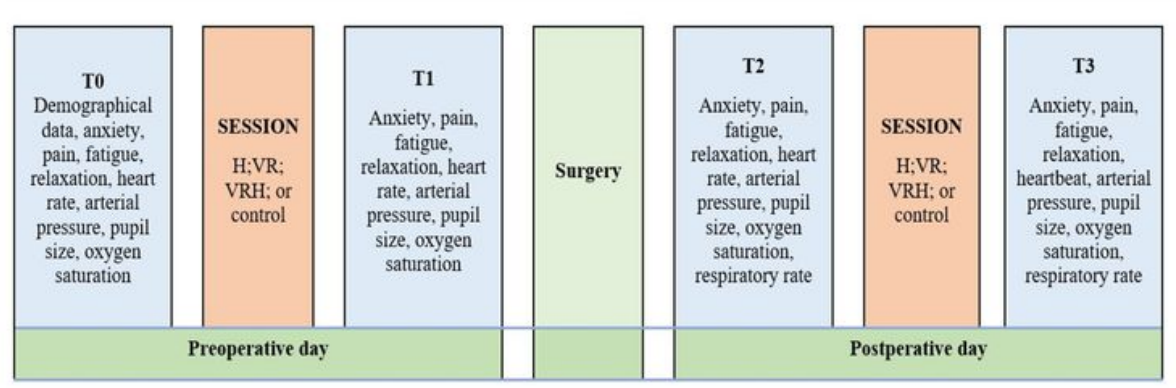

\section{Results}

30 patients dropped out in post surgery due to medical reasons or extreme fatigue. Anxiety decreased and relaxation increased in all groups, including control group. We cannot affirm that one technique is better than another is. Nevertheless, this study helps to expand the knowledge regarding application of virtual reality, hypnosis and virtual reality hypnosis in the specific contexts of cardiac surgery and intensive care units. Additional studies are required to compare and evaluate the costs-effectiveness of these techniques for critical care patients and caregivers.

\section{Methods}

Population: 100 cardiovascular surgery (CVS) patients (24 women, 76 men, $66 \pm 11 \mathrm{y}$.) were randomised to receive 20 minutes sessions of hypnosis $(H)$, virtual reality (VR), virtual reality hypnosis (VRH) or control group before and after surgery. Testing: Before and after sessions, anxiety, pain, fatigue and relaxation were assessed with Visual Analogical Scales (VAS) from 0 to 10 .

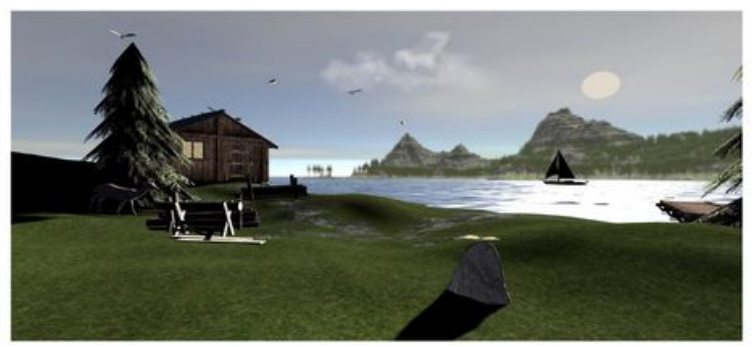

\section{Figure 1}

Graphical abstract 


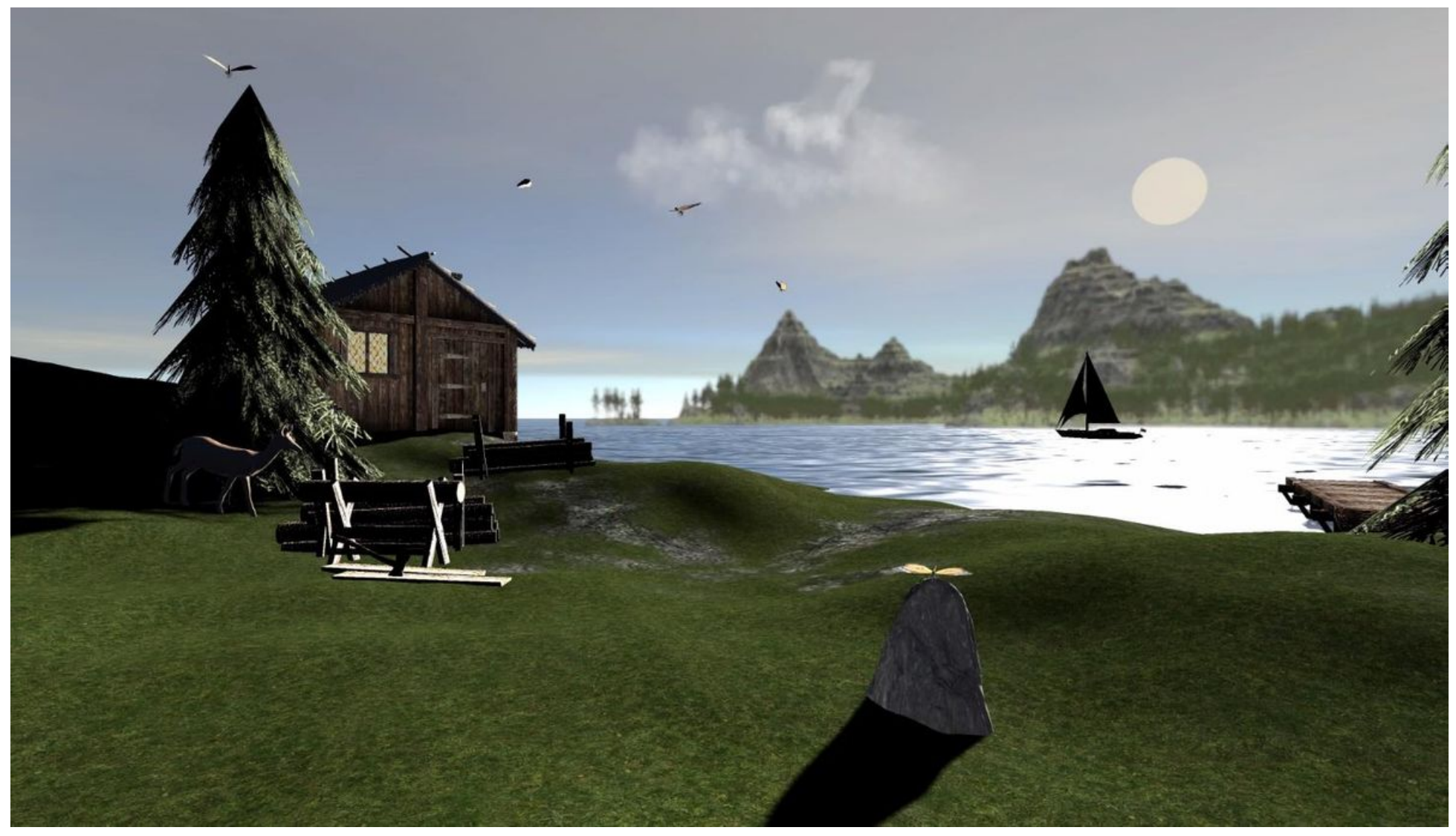

Figure 2

Virtual reality landscape designed by Oncomfort@

\begin{tabular}{|c|c|c|c|c|c|c|}
\hline $\begin{array}{c}\text { T0 } \\
\text { Demographical } \\
\text { data, anxiety, } \\
\text { pain, fatigue, } \\
\text { relaxation, heart } \\
\text { rate, arterial } \\
\text { pressure, pupil } \\
\text { size, oxygen } \\
\text { saturation }\end{array}$ & $\begin{array}{c}\text { SESSION } \\
\text { H;VR; } \\
\text { VRH; or } \\
\text { control }\end{array}$ & $\begin{array}{l}\text { T1 } \\
\text { Anxiety, pain, } \\
\text { fatigue, } \\
\text { relaxation, heart } \\
\text { rate, arterial } \\
\text { pressure, pupil } \\
\text { size, oxygen } \\
\text { saturation }\end{array}$ & Surgery & $\begin{array}{c}\text { T2 } \\
\text { Anxiety, pain, } \\
\text { fatigue, } \\
\text { relaxation, heart } \\
\text { rate, arterial } \\
\text { pressure, pupil } \\
\text { size, oxygen } \\
\text { saturation, } \\
\text { respiratory rate }\end{array}$ & $\begin{array}{c}\text { SESSION } \\
\text { H;VR; } \\
\text { VRH; or } \\
\text { control }\end{array}$ & $\begin{array}{c}\text { T3 } \\
\text { Anxiety, pain, } \\
\text { fatigue, } \\
\text { relaxation, } \\
\text { heartbeat, arterial } \\
\text { pressure, pupil } \\
\text { size, oxygen } \\
\text { saturation, } \\
\text { respiratory rate }\end{array}$ \\
\hline \multicolumn{3}{|c|}{ Preoperative day } & & \multicolumn{3}{|c|}{ Postperative day } \\
\hline
\end{tabular}

\section{Figure 3}

Study design, times and assessments. H: Hypnosis, VR: Virtual Reality, VRH: Virtual Reality Hypnosis. 


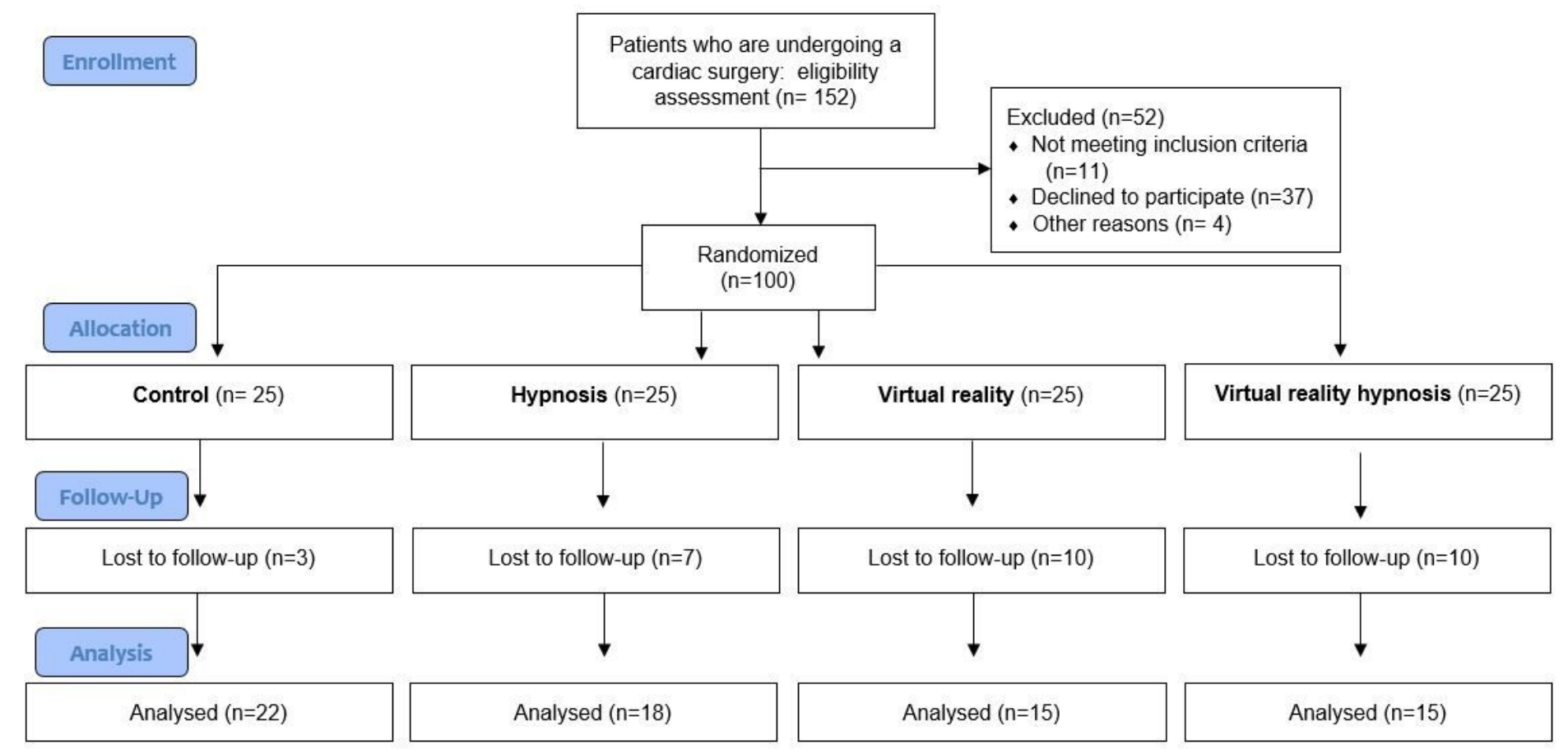

Figure 4

CONSORT Flow Diagram

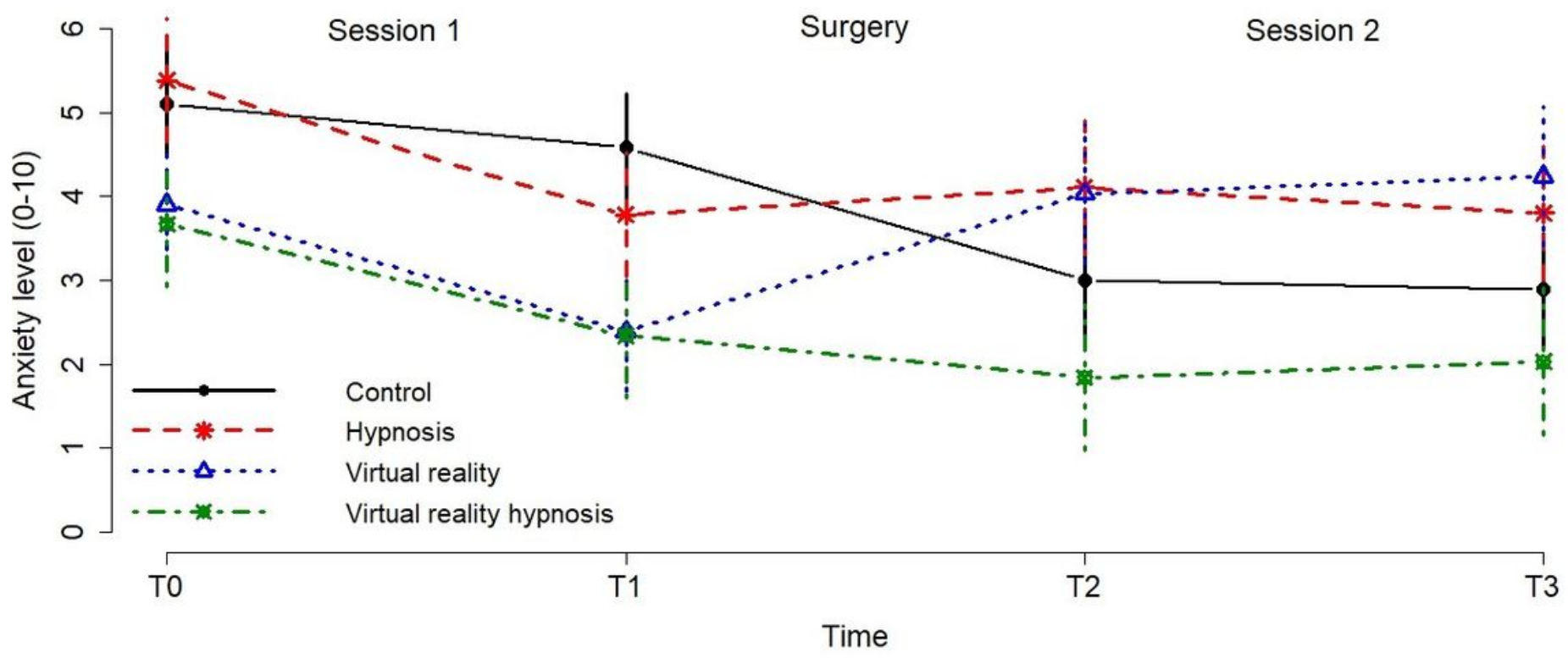

Figure 5

Evolution of anxiety during pre and post-surgery (by time by group) 


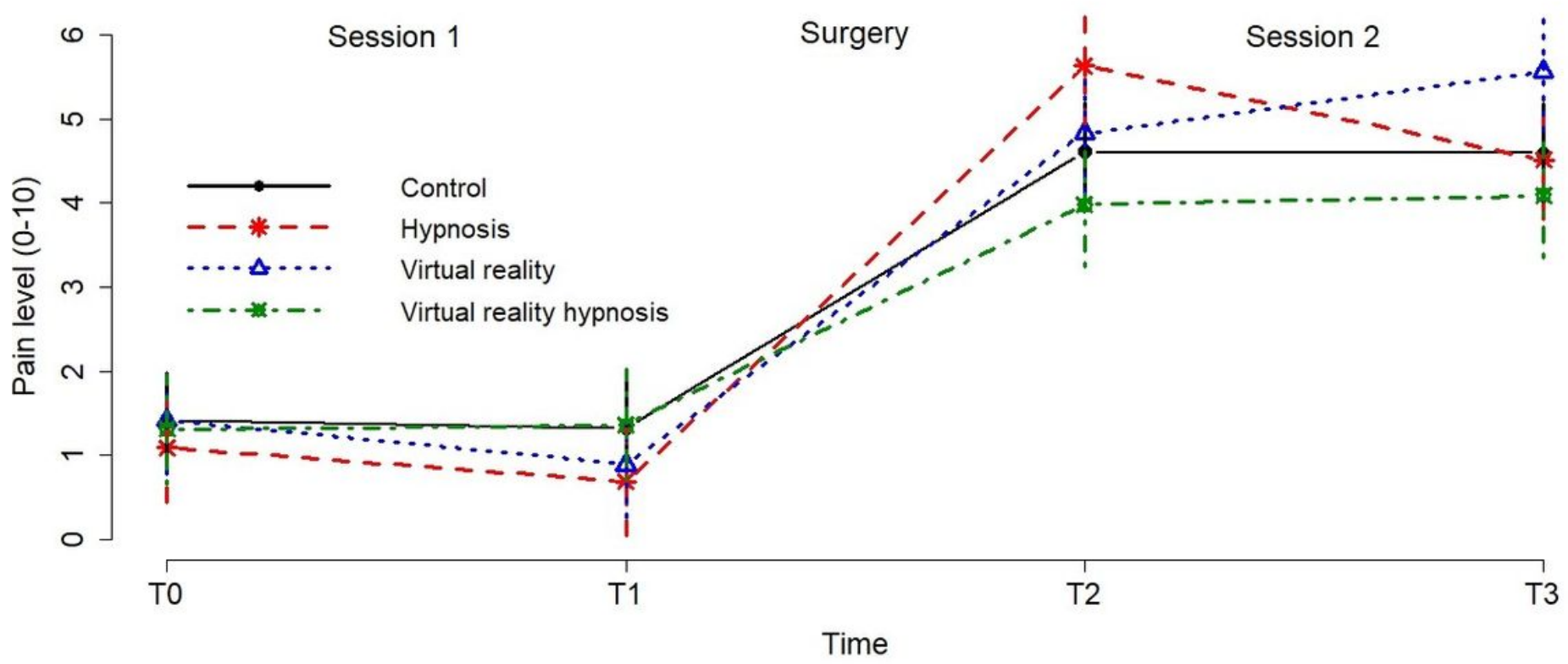

Figure 6

Evolution of pain during pre and post-surgery (by time by group)

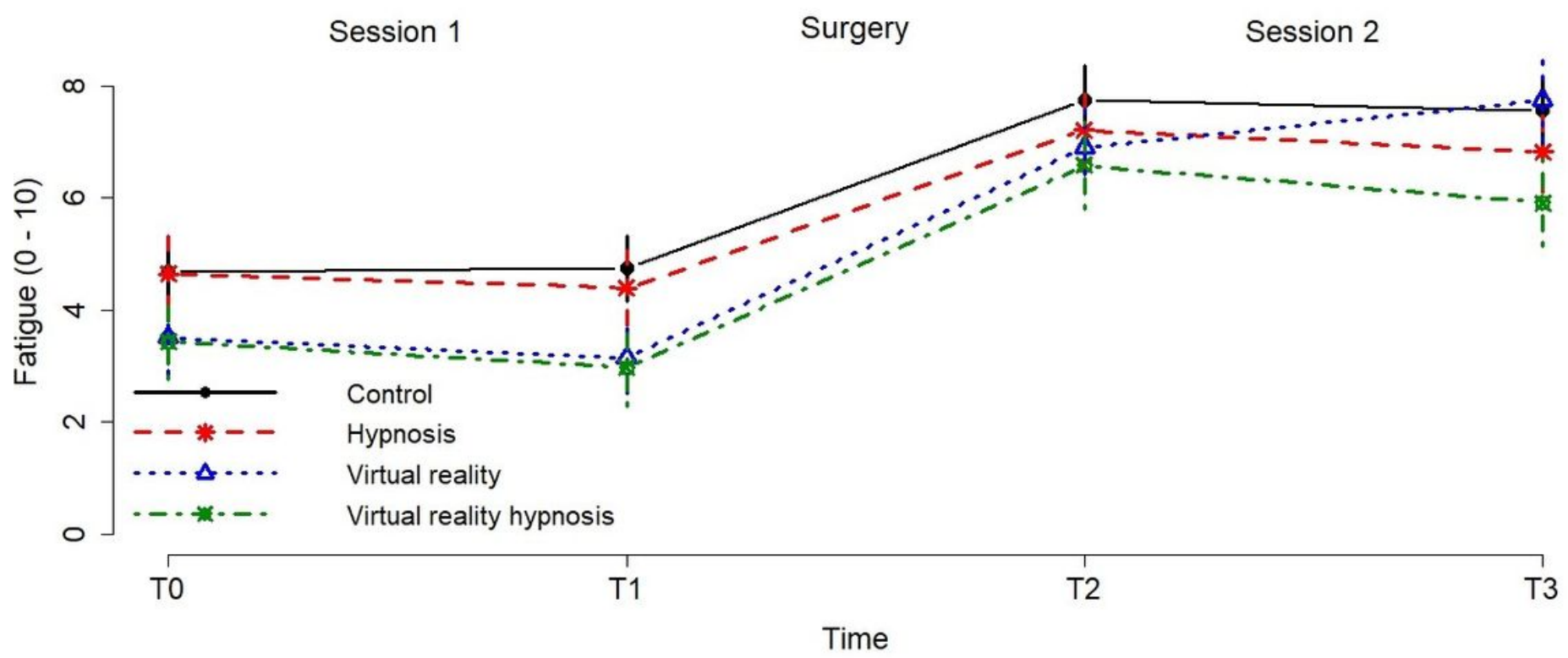

Figure 7

Evolution of relaxation during pre and post-surgery (by time by group) 
Session 1

Surgery

Session 2

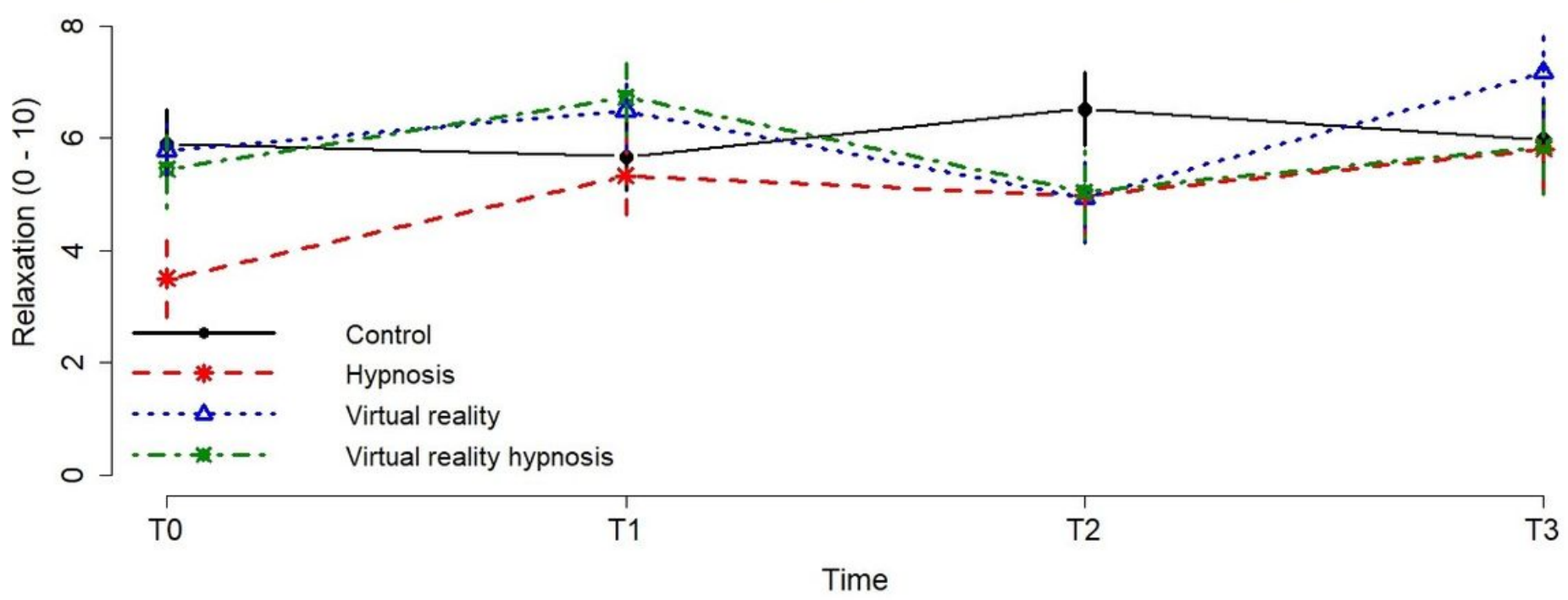

Figure 8

Evolution of fatigue during pre and post-surgery (by time by group)

\section{Supplementary Files}

This is a list of supplementary files associated with this preprint. Click to download.

- RousseauxAdditionnalfile1.pdf 